\title{
An Observational Study of Umbilical Cord Clamping and Care Practices during Home Deliveries in Central Uganda
}

\author{
Divya Shakti ${ }^{1, *}$, Veena Singh ${ }^{2}$, Gertrude Nakigozi $^{3}$, Sarah Kiguli ${ }^{4}$ and Deepak Kamat ${ }^{1}$ \\ ${ }^{1}$ Department of Pediatrics, Children's Hospital of Michigan, 3901 Beaubien St, Detroit, MI 48201, USA \\ ${ }^{2}$ Johns Hopkins Bloomberg School of Public Health, 615 N Wolfe St, Baltimore, MD 21205, USA \\ ${ }^{3}$ Rakai Health Sciences Program, P.O. Box 279, Kalisizo, Rakai, Uganda \\ ${ }^{4}$ Makerere University College of Health Sciences, Kampala, Uganda
}

\begin{abstract}
Delayed umbilical cord clamping and care practices have important implications for infant iron stores and neonatal survival. This is especially important in countries like Uganda, where there is a high prevalence of anemia in women and children coupled with a high newborn mortality rate. This study assesses cord clamping and care practices in home births in a coverage area of 12 health centers in 4 districts near Kampala, Uganda. We interviewed 147 women, most of who had at least primary school education and delivered their babies in the homes of traditional birth attendants. Only $65 \%$ of the persons conducting delivery washed hands, and most wore gloves. Most frequent cord ties were threads $(86.7 \%)$, and glove rims $(8.3 \%)$. Cords were cut with clean instruments in most $(93.1 \%)$ deliveries. During cord clamping, newborn was positioned at a higher level than mother in $59 \%$, delayed clamping ( $\geq 3$ mins) was reported in $52 \%$. Combination of delayed clamping and positioning of newborn at mother's level or lower was reported in only $19 \%$. Substances used for cord care included surgical spirit (42.4\%), local herbs (24.5\%), powder (22.6\%), ash (21.6\%), saline water $(10.3 \%)$, and tea $(2.8 \%)$. Cord care instructions given most commonly were: cleaning with warm saline water $(27 \%)$, spirit or antiseptics (25\%), and herb application (7\%). Awareness regarding cord infections was poor $(20 \%)$. Mother's education level, and age were not associated with cord clamping or care practices. Our study indicates scope for interventions to help improve hemoglobin levels in infancy. Education regarding cord care practices may reduce infections.
\end{abstract}

Keywords: Umbilical cord care, umbilical cord clamping, newborn care practices, home childbirth, maternal health services.

\section{INTRODUCTION}

Umbilical cord clamping and care practices have significant implications for infant iron stores and neonatal survival. Iron has an important role in normal neuro-motor development [1]. Hospital-based clinical trials of delayed umbilical cord clamping have repeatedly shown increased iron stores, and in some cases better hemoglobin level in early infancy, both in the developing and developed worlds [2-4]. Uganda has a high prevalence of anemia in the mothers and children, where $23 \%$ of women aged $15-49$ years and $49 \%$ of children aged 6-59 months are anemic [5].

Poor umbilical cord care has a strong association with neonatal mortality [6]. Home births are associated with higher risk of cord infections as compared to hospital births [7, 8]. Around $42 \%$ of pregnant women deliver in their homes, unsupervised by a trained health professional, mainly under the care of the traditional birth attendants (TBA) in Uganda [5].

The prevalent umbilical cord related birthing practices in Ugandan home births are not well known.

*Address correspondence to this author at the Division of Pediatric Cardiology, Children's Hospital of Michigan, 615 N Wolfe St, Baltimore, MD 21205, USA; Tel: +1 601-815-1432; Fax: +1 601-984-5283;

E-mail: drdivyashakti@gmail.com
Their knowledge can help formulate strategies to improve neonatal outcomes. Our study was a logical step towards learning the prevalent birth practices in home births in Uganda with emphasis on umbilical cord clamping and care practices.

\section{METHODS}

\section{Study Setting}

Uganda is a developing country in sub-Saharan Africa. Our study coverage area included 4 districts from 3 regions of Uganda, namely Kampala (Kampala region), Kayunga (East central region), Wakiso and Mpigi (both from Central region). We enrolled participants within a 60 miles distance from Kampala.

Since the initial immunization visits after birth (including home births) occur at around 1-3 months of age in Uganda, with coverage of 63 to $93 \%$, the study was designed to identify and enroll participants at 12 health centers serving the study population [5].

\section{Study Design and Participants}

The Institutional review boards at Wayne State University and Makerere Medical School, Uganda 
approved our study. We undertook this descriptive questionnaire-based study with a convenient sampling approach. Written permission from Public Health Department to work with the health centers was obtained. After pre-testing of the questionnaires, data collection was carried out in the month of November 2009. All the questionnaires and consent forms were officially translated to Luganda, the most commonly spoken local language in the region. Written informed consents were obtained from participants.

The enrollment of participants was carried out at immunization centers under the health centers, and also at the homes of mothers in villages. The mothers with infants born in past 3 months coming to health centers for immunizations were asked about the place of their delivery and screened for enrollment in the study. Help of community workers at health centers was sought to identify women in villages who recently gave birth at home and their TBA contacts.

The inclusion criteria were: Women residing in the study area that delivered full term singleton infants at home by normal vaginal delivery in previous 3 months. The exclusion criteria were: Pregnancy or birth complicated by multiple gestation, mal-presentation, congenital defects, and asphyxia. A checklist at the beginning of each questionnaire was included to ensure the eligibility of the participants.

Four research assistants who were local undergraduate students fluent in English and Luganda were hired and trained by the investigators to administer the questionnaires in the local language in a standard fashion. Information on the sociodemographic profile of the mother, the head of household, the infant, intra-partum practices, umbilical cord clamping and care practices, and awareness of cord infections was collected. Cord stump length was estimated by the mothers with the aid of a ruler provided at the time of the interview. Investigators supervised conduction of all the interviews. Participants were compensated for their time with 3000 Ugandan Shillings $(\sim \$ 1)$, at the end of their interview. This amount was pre-determined to be a non-coercive amount by the abovementioned Institutional review boards.

The data were coded and analyzed using Intercooled STATA-version 9. Means (SD) and frequency (percentages) were used to describe the continuous and categorical data respectively. Chi square test was used to test for any associations with socio-economic parameters and cord practices. $\mathrm{P}$ value of $<0.05$ was considered significant.

\section{RESULTS}

Altogether 155 participants were interviewed, of which 8 were excluded (7 infants were older than 120days and 1 participant was grandmother of the index child). The results presented are drawn from 147 mothers (age range: 16-42 yrs) who gave birth in the previous 3 months (mean age of infant $49.3 \pm 32.2$ days). About $8 \%$ of mothers and head of the households were illiterate. Forty three percent of the mothers, and $50 \%$ of the head of the households had at least secondary level education. Majority (98\%) of home births were conducted by the TBAs, mostly at TBAs' home (86\%). Table 1 summarizes the sociodemographic characteristics of the families.

The intra-partum practices reported by mothers are summarized in Table 2. Cord was cut using: new razor blade $(126,86.9 \%)$, other razor blades $(7,4.8 \%)$, sterilized scissors $(7,4.8 \%)$, non-sterilized scissors $(3$, $2.1 \%)$, and surgical blades (2, 1.4\%). Use of medications to help uterine contractions was reported by $38 / 142 \quad(26.7 \%)$ mothers. The uterotonic medications reported were: herbal medicine (58.8\%), African tea or tea-leaves (35.3\%) and hot tea along with herbs $(5.9 \%)$. Medication use to stop bleeding at birth was reported by $43 / 147(29.2 \%)$. Ergometrine $(27.8 \%)$ was the commonest medication reported, followed by mention of 'some injection' (27.8\%), herbal medicine $(22.2 \%)$, acetaminophen/water/soda (11.1\%), pitocin (5.6\%) and African tea (5.6\%).

\section{Cord Clamping Practices}

At the time of cord clamping, the reported position of the newborn relative to the level of the mother (defined as the level of uterus of mother) was: above in $85 / 145(58.6 \%)$, at the same level in $57(39.3 \%)$ and below in $3(2.1 \%)$. The average time of cord clamping reported was $3.05 \pm 7.1 \mathrm{~min}$ (range $3 \mathrm{sec}-60 \mathrm{~min}$ ). The cord was clamped within $1 \mathrm{~min}$ in $46 / 147$ (31.3\%), between 1-3 $\mathrm{min}$ in $25(17 \%)$ and after 3 mins in 76 (51.7\%). There was no significant association between early or late cord clamping and the position of newborn relative to mother's uterus (Table $\mathbf{3}$ ).

Cord milking before cord clamping was reported in $26 / 145$ (18\%). Among these, milking of cord towards the newborn was reported in $26.9 \%$, towards placenta in $53.8 \%$, and the direction of milking was not known in $19.2 \%$. 
Table 1: Socio-Demographic Characteristics Mothers, Head of Households and Infants

\begin{tabular}{|c|c|}
\hline$(\mathrm{N}=147)$ & $\mathrm{N}(\%)$ or Mean (SD) \\
\hline \multicolumn{2}{|l|}{ Characteristics of Mothers } \\
\hline \multicolumn{2}{|l|}{ Age (yrs) } \\
\hline$<18$ & $4(2.7)$ \\
\hline $18-20$ & $43(29.2)$ \\
\hline $21-25$ & $58(39.5)$ \\
\hline $26-30$ & $26(17.7)$ \\
\hline $31-35$ & $13(8.8)$ \\
\hline$>35$ & $3(2.0)$ \\
\hline Mean age (yrs) & $24.0 \pm 5.0$ \\
\hline \multicolumn{2}{|l|}{ Education } \\
\hline No formal education & $12(8.2)$ \\
\hline Primary & $71(48.3)$ \\
\hline Secondary and above & $64(43.5)$ \\
\hline \multicolumn{2}{|c|}{ Characteristics of Head of Household $(\mathrm{HOH})$} \\
\hline \multicolumn{2}{|l|}{ Age (yrs) } \\
\hline$<21$ & $5(3.4)$ \\
\hline $21-25$ & $35(23.8)$ \\
\hline $26-30$ & $31(21.1)$ \\
\hline $31-40$ & $42(28.6)$ \\
\hline$>40$ & $34(23.1)$ \\
\hline Mean age (yrs) & $31.1 \pm 8.0$ \\
\hline Male & $138(93.9)$ \\
\hline \multicolumn{2}{|l|}{ Education } \\
\hline No formal education & $11(7.5)$ \\
\hline Primary & $43(29.2)$ \\
\hline Secondary and above & $74(50.3)$ \\
\hline Unsure & $19(13.0)$ \\
\hline \multicolumn{2}{|l|}{ Occupation } \\
\hline Farming & $43(29.4)$ \\
\hline Trading & $38(26.0)$ \\
\hline Service provision & $48(32.9)$ \\
\hline Casual labor & $5(3.4)$ \\
\hline Unemployed & $4(2.7)$ \\
\hline Other & $8(5.5)$ \\
\hline \multicolumn{2}{|l|}{ Characteristics of Infants } \\
\hline Age (days) & $49.3 \pm 32.2$ \\
\hline Female & $69(47.0)$ \\
\hline \multicolumn{2}{|l|}{ Birthplace } \\
\hline TBA's place & $127(86.4)$ \\
\hline Home & $19(13.0)$ \\
\hline Field & $1(0.6)$ \\
\hline \multicolumn{2}{|l|}{ Delivery conducted by } \\
\hline TBA & $144(98.0)$ \\
\hline Mother/relative & $3(2.0)$ \\
\hline
\end{tabular}

of
Table 2: Intra Partum Practices

\begin{tabular}{|c|c|}
\hline Practices $(\mathrm{N}=147)$ & $\mathbf{N}(\%)$ \\
\hline \multicolumn{2}{|c|}{ Hand washing by person conducting delivery $(\mathrm{N}=146)$} \\
\hline Yes & $95(65.0)$ \\
\hline No & $8(5.5)$ \\
\hline Unsure & $43(29.5)$ \\
\hline Soap-water used for hand washing & $88 / 93(94.6)$ \\
\hline Glove use reported & $96 / 98(98.0)$ \\
\hline \multicolumn{2}{|c|}{ Position of mother during delivery $(\mathrm{N}=147)$} \\
\hline On ground & $48(32.6)$ \\
\hline Above ground (on bed/table) & $99(67.4)$ \\
\hline \multicolumn{2}{|l|}{ Cord tie $(N=143)$ : } \\
\hline Thread & $124(86.7)$ \\
\hline Glove rim & $12(8.4)$ \\
\hline Cloth & $4(2.7)$ \\
\hline Rubber band and others & $3(2.1)$ \\
\hline \multicolumn{2}{|l|}{ Cord Cutting instrument $(\mathrm{N}=145)$} \\
\hline Razor blade & $133(91.7)$ \\
\hline New razor blade & $126 / 133(97.7)$ \\
\hline Scissors & $10(6.9)$ \\
\hline Sterilized scissors & $7 / 10(70.0)$ \\
\hline Surgical blade & $2(1.4)$ \\
\hline
\end{tabular}

Clamping of the cord before placenta removal was reported in 111/147 (75.5\%), cord clamping after placenta removal was reported in 22 (15\%), and 14 $(9.5 \%)$ mothers were not sure of the temporal sequence of cord clamping and placenta removal.

\section{Cord Application Practices}

Mean estimated cord stump length was $5.9 \pm 1.8$ $\mathrm{cm}$ (range 2 to $13 \mathrm{~cm}$ ). Substance application to umbilical cord stump immediately after cord cutting was reported in $33 / 141(23.4 \%)$, while applications later at home were reported in 96/144 (66.7\%). The commonest substance applied to cord stump immediately after cord cutting was surgical spirit (14, $43.8 \%)$, followed by saline water $(4,12.5 \%)$, herbs (8, $25 \%)$, ash $(2,6.2 \%)$, dry cotton and others (4, 12.5\%). Applications to cord stump anytime after birth was reported in 106/143 (74\%). The commonest substance used was surgical spirit again (45/106, 42.4\%). Multiple substance applications were common. Figure 1 shows the distribution of substance applications to the cord stump. The instructions for cord care given to mothers varied widely. The commonest cord care instructions 
Table 3: Distribution of Position of Infant and Cord Clamping Timings

\begin{tabular}{|c|c|c|c|}
\hline \multirow{2}{*}{ Timing of Cord Clamping } & \multicolumn{2}{|c|}{ Position of Newborn Relative to Mother's Uterus $(\mathrm{N}=145)$} & \multirow{2}{*}{ p-Value } \\
\hline & Above & Below/same & \\
\hline$<1 \mathrm{~min}$ & $5(3.4 \%)$ & $6(4.1 \%)$ & \multirow{2}{*}{0.356} \\
\hline$\geq 1 \mathrm{~min}$ & $80(55.2 \%)$ & $54(37.2 \%)$ & \\
\hline$<3 \min$ & $39(27 \%)$ & $32(22 \%)$ & \multirow{2}{*}{0.377} \\
\hline$\geq 3 \min$ & $46(32 \%)$ & $28(19 \%)$ & \\
\hline
\end{tabular}

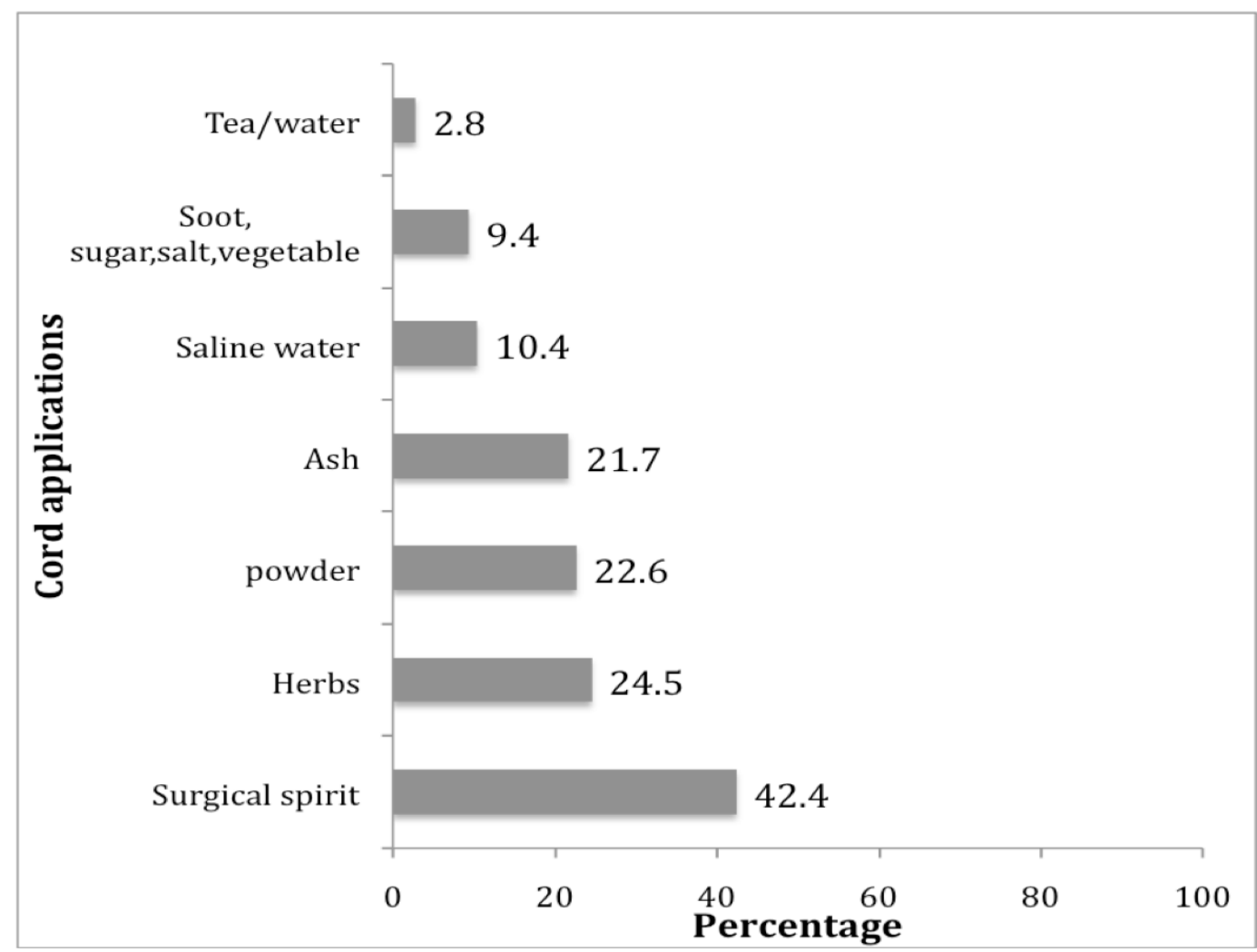

Figure 1: Substances Applied (in Percentages) to Cord Stump Anytime After Birth.

This includes multiple cord applications; therefore the percentages of those that applied the particular substance do not add up to 100 .

given were- clean with warm saline water (27\%), apply spirit or antiseptics (25\%), and apply herbs (7\%). The average time of cord separation reported was $4.6 \pm 2.1$ days.

\section{Awareness of Cord Infection}

Twenty percent of mothers had ever heard of cord infections. Occurrence of cord infection was reported by $2 \%$ of mothers. Most ( $93 \%$ ) mothers said that they would take their child to health facility if cord infection were suspected. Immunization against tetanus through vaccination during recent pregnancy was reported by $89 \%$ mothers and through vaccination in past 3 years if not during the recent pregnancy in $1.4 \%$ mothers.
No significant associations (data not shown) were noted between maternal age, maternal education or infant gender and hand washing by delivering person, substance application to cord stump, cord clamping time, and awareness of cord infections.

\section{DISCUSSION}

Our findings give a snapshot of the prevalent cord clamping and care practices in home births in four districts of central Uganda. Our findings also emphasize the important role of traditional birth attendants in the delivery of maternal and newborn care in our study population, suggesting that their incorporation in policy making and implementation of 
optimal maternal and newborn care practices would be important.

Uganda Demographic and Health Survey 2011 notes that $42 \%$ of pregnant women in Uganda deliver in their homes, unsupervised by a trained health professional, mainly under the care of the TBA (18\%) and relatives (15\%) [5]. Our finding of majority (86.4\%) of home births occurring at TBA's place and almost all births conducted by the TBA (98\%) indicates the important role of TBAs in birthing practices in this community setting.

The use of gloves was almost universal and might reflect the awareness of potential risk of transmission of HIV/AIDS while conducting deliveries [5]. Emphasizing universal hand washing by the person conducting delivery, even when gloves are used would be helpful. Similarly, reiteration of use of sterile instruments for cord cutting in all cases is imperative. Preponderance of use of thread as cord-tie and new razor blades for cord cutting may be related to the popularity of 'mama kits' that contain them. The use of rim of the gloves as a cord tie was an interesting and possibly safe improvisation. The use of glove rims as cord tie is common practice in hospitals of Uganda (personal observation in hospital births and personal communication with hospital midwives).

Perceived common utero-tonic agents included herbal medicines and tea. Cyclotides derived from Oldenlandia affinis plant have uterotonic properties [9] and tea made from this has been used in some parts of Africa to facilitate childbirth [10]. The identity of herbs used was not established in our study.

Variations in cord clamping practices were noted in our study population. The combination of delayed cord clamping and a lower positioning of newborn, that enhances transfusion of blood to newborn, were reported in only $19 \%$. Overall, the cord clamping practices did not favor distribution of blood towards the newborn in our study population. This indicates need for an intervention to improve cord-cutting practices to allow transfusion of blood from placenta to newborn.

Cord stump that is cut too short might predispose to bleeding if ligature is loose. On the other hand, too long a cord stump can predispose to its soiling and infection. WHO guidelines recommend cutting the cord $2-3 \mathrm{~cm}$ from base [11]. In our study, the estimated length of cord stump left during cord cutting was $5.9 \pm 1.8 \mathrm{~cm}$.
While WHO recommends clean and dry cord care in all settings, substance application to cord stump until separation is common in many developing countries [12]. Use of surgical spirit has not been recommended as it delays cord separation [13]. Recent evidence supports use of chlorhexidine in home births in developing world settings to reduce omphalitis and mortality in neonates [14]. Almost three quarters of our study population reported substance application to cord stump at some point after cord cutting until separation, compared to $49 \%$ substance application rate in another study in a different region of Uganda [15]. Chlorhexidine use was not specifically reported in our population. Surgical spirit application was the commonest followed by use of saline water, also noted in the study by Waiswa et al. [15]. Health care workers encourage the use of salty water and spirit; however, the evidence on use of salt water is little [16]. It could be speculated that hypertonic and clean saline water may have a desiccant effect on the cord stump, however there is potential of contamination of this solution, hence risk of infection. Other substances (e.g. soot, sugar, salt, vegetable, ash, powder) used for application were potentially hazardous. This is especially concerning since $10 \%$ of mothers in our study population reported no immunization against tetanus.

Our study limitations include those inherent to an observational study design, use of convenience sampling that limits generalizability, and recall bias. We may have over-estimated the proportion of home births conducted by TBAs given possible selection bias related to convenience sampling. Our attempts to minimize recall bias included interview of mothers who gave birth recently (past 3 months), using a ruler scale to improve accuracy of recall of cord stump length, and using events at the time of birth to estimate cordclamping time by mothers.

Direct observation of deliveries at home to assess the cord clamping and care practices, comparing the practices reported by recipients and providers of maternal and newborn care on a larger scale could be the logical next step. Assessing the readiness and receptivity of both the recipients and providers towards adopting a change in their practices before making recommendations is important. New policies prioritizing delivery of integrated maternal-newborn programs including the use of community strategies have been developed but these have not yet been fully operationalized in Uganda. 


\section{CONCLUSIONS}

The cord clamping and care practices noted in our study inform about the prevalent practices in this community and indicate the scope of intervention and potential of education for improving newborn care. Additionally, the important role of traditional birth attendants in our study population also emphasizes a need for their involvement in policy making and implementation of optimal maternal and newborn care practices.

\section{LIST OF ABBREVIATIONS}

$$
\begin{array}{ll}
\text { TBA } & \text { Traditional Birth Attendants } \\
\mathrm{SD} & =\text { Standard Deviation } \\
\text { HIV/AIDS }= & \begin{array}{l}
\text { Human Immunodeficiency virus/ Acquired } \\
\text { Immune Deficiency Syndrome }
\end{array} \\
\text { WHO }= & \text { World Health Organization }
\end{array}
$$

\section{ACKNOWLEDGEMENTS AND CREDITS}

We acknowledge the Sarnaik Endowment, Children's Research Center of Michigan for funding this study (grant number: 07/2009). We thank the Makerere University College of Health Sciences for facilitating the study. We acknowledge the help of participating health centers at: Kayunga, Ndejje, Banda, Nansana, Mende, Kasenge, Bakka, Kakonge, Sserinya, Katooke, Mbogo, Kawempe, Kisenyi, Kiruddu, Kasangati, Gombe, and Wakiso.

\section{REFERENCES}

[1] Lozoff B. Iron deficiency and child development. Food Nutr Bull 2007; 28(4 Suppl): S560-71. http://dx.doi.org/10.1542/peds.2005-1156

[2] Chaparro CM, Neufeld LM, Tena Alavez G, Eguia-Liz Cedillo $R$, Dewey KG. Effect of timing of umbilical cord clamping on iron status in Mexican infants: a randomised controlled trial. Lancet 2006; 367: 1997-2004. http://dx.doi.org/10.1016/S0140-6736(06)68889-2
[3] Ceriani Cernadas JM, Carroli G, Pellegrini L, et al. The effect of timing of cord clamping on neonatal venous hematocrit values and clinical outcome at term: a randomized, controlled trial. Pediatrics 2006; 117: e779-86.

[4] Hutton EK, Hassan ES. Late vs. early clamping of the umbilical cord in full-term neonates: systematic review and meta-analysis of controlled trials. JAMA 2007; 297: 1241-52. http://dx.doi.org/10.1001/jama.297.11.1241

[5] Uganda Bureau of Statistics (UBOS) and ICF International Inc. 2012. Uganda Demographic and Health Survey 2011. Kampala, Uganda: UBOS and Calverton, Maryland:ICF International Inc.

[6] Eregie CO, Ofovwe G. Factors associated with neonata tetanus mortality in northern Nigeria. East Afr Med J 1995; 72: $507-9$

[7] Faridi MM, Rattan A, Ahmad SH. Omphalitis neonatorum. J Indian Med Assoc 1993; 91: 283-5.

[8] Sawardekar KP. Changing spectrum of neonatal omphalitis. Pediatr Infect Dis J 2004; 23: 22-6. http://dx.doi.org/10.1097/01.inf.0000105200.18110.1e

[9] Gran L. Oxytocic principles of Oldenlandia affinis. Lloydia 1973; 36: 174-8.

[10] Gunasekera S, Daly NL, Anderson MA, Craik DJ. Chemical synthesis and biosynthesis of the cyclotide family of circular proteins. IUBMB Life 2006; 58: 515-24. http://dx.doi.org/10.1080/15216540600889532

[11] World Health Organization. Care of the umbilical cord Maternal and new born health/safe motherhood. World Health Organization; Geneva, Switzerland 1998.

[12] Capurro H. The WHO Reproductive Health Library. Geneva: World Health Organization; Topical umbilical cord care at birth: RHL practical aspects: RHL practical aspects (last revised: 30 September 2004). The WHO Reprodutive Health Library; Geneva: World Health organization.

[13] Zupan J, Garner P, Omari AA. Topical umbilical cord care at birth. Cochrane Database Syst Rev 2004; (3): CD001057. http://dx.doi.org/10.1002/14651858.cd001057.pub2

[14] Imdad A, Mullany LC, Baqui AH, et al. The effect of umbilical cord cleansing with chlorhexidine on omphalitis and neonatal mortality in community settings in developing countries: a meta-analysis. BMC Public Health 2013; 13(Suppl 3): S15. http://dx.doi.org/10.1186/1471-2458-13-S3-S15

[15] Waiswa P, Peterson S, Tomson G, Pariyo GW. Poor newborn care practices - a population based survey in eastern Uganda. BMC Pregnancy Childbirth 2010; 10: 9. http://dx.doi.org/10.1186/1471-2393-10-9

[16] Waiswa P, Kemigisa M, Kiguli J, Naikoba S, Pariyo GW, Peterson S. Acceptability of evidence-based neonatal care practices in rural Uganda - implications for programming. BMC Pregnancy Childbirth 2008; 8: 21.

http://dx.doi.org/10.1186/1471-2393-8-21

\section{http://dx.doi.org/10.6000/1929-4247.2016.05.01.4}

(C) 2016 Shakti et al.; Licensee Lifescience Global.

This is an open access article licensed under the terms of the Creative Commons Attribution Non-Commercial License (http://creativecommons.org/licenses/by-nc/3.0/) which permits unrestricted, non-commercial use, distribution and reproduction in any medium, provided the work is properly cited. 